\title{
DEMANDA SETORIAL DE TRABALHO POR QUALIFICAÇÃO NO PARANÁ
}

\author{
Lorena Regina Oliveira, Universidade Estadual do Norte do Paraná - UENP \\ lorena.regina@uenp.edu.br \\ Paulo Rogerio Alves Brene, Universidade Estadual do Norte do Paraná - Campus Cornélio Procópio \\ paulobrene@uenp.edu.br \\ Umberto Antonio Sesso Filho, Universidade Estadual de Londrina \\ umasesso@uel.br \\ Emerson Guzzi Zuan Esteves, Universidade Estadual de Londrina \\ egzesteves@gmail.com
}

\begin{abstract}
RESUMO
O objetivo principal deste trabalho foi mensurar a demanda setorial de trabalho por escolaridade do Paraná - Restante do Brasil, sendo possível apontar quais os setoreschave para o desenvolvimento econômico e social das regiões. A metodologia utilizada o sistema de insumo-produto inter-regional Paraná-restante do Brasil, para estimar a capacidade de geração de emprego por qualificação de cada setor da economia, fazendo o uso dos geradores de emprego (total, direto, indireto e induzido) dado o nível de escolaridade, apontará o efeito transbordamento e os setores que possuem maior participação percentual na geração de empregos. Os principais resultados apresentaram que o setor com maior transbordamento do estado do Paraná - restante do Brasil foi o de Alojamento (44) com 85,9\% para Ensino Fundamental, 87,3\% para o Ensino Médio e $84,4 \%$ para o Ensino Superior. Os setores que mais geraram empregos no estado do Paraná para o Ensino Fundamental foi o setor de Alojamento (38) com 7.96\%, no Ensino Médio o setor de Atividades de vigilância, segurança e investigação (50) com $12 \%$ e para o Ensino Superior o setor Educação Privada (52) com 20\% dos empregos gerados.
\end{abstract}

Palavras-chaves: Insumo-produto, Inter-regional, Emprego, Escolaridade, Cenários econômicos.

Data de recebimento: 23/01/2020

Data do aceite de publicação: 04/11/2020

Data da publicação: $30 / 12 / 2020$ 


\title{
SECTORIAL DEMAND OF WORK FOR QUALIFICATION IN PARANÁ
}

\author{
Lorena Regina Oliveira, Universidade Estadual do Norte do Paraná - UENP \\ lorena.regina@uenp.edu.br \\ Paulo Rogerio Alves Brene, Universidade Estadual do Norte do Paraná - Campus Cornélio Procópio \\ paulobrene@uenp.edu.br \\ Umberto Antonio Sesso Filho, Universidade Estadual de Londrina \\ umasesso@uel.br \\ Emerson Guzzi Zuan Esteves, Universidade Estadual de Londrina \\ egzesteves@gmail.com
}

\begin{abstract}
The main objective of this work was to measure the sectoral labor demand for schooling in Paraná - Rest of Brazil, pointing out which are the key sectors for the economic and social development of the regions. The methodology used the Paraná-remaining interregional input-output system of Brazil, to estimate the capacity of job creation by qualification of each sector of the economy, making use of the job generators (total, direct, indirect and induced). Given the level of education, it will point to the spillover effect and the sectors that have the highest percentage participation in job creation. The main results showed that the most overflowing sector in the state of Paraná - rest of Brazil was Accommodation (44) with $85.9 \%$ for Elementary School, 87.3\% for High School and $84.4 \%$ for High School. Higher. The sectors that generated the most jobs in the state of Parana for Elementary Education were the Accommodation sector (38) with $7.96 \%$, in High School the Surveillance, Security and Investigation Activities sector (50) with $12 \%$ and for Higher Education. the Private Education sector (52) with $20 \%$ of the jobs generated.
\end{abstract}

Keywords: Input-output, interregional, employment, education, economic scenarios.

\section{INTRODUÇÃO}

Após a abertura comercial na década de 1990 o mercado no Brasil começa a se relacionar com o internacional, iniciando um novo período de desenvolvimento no país. O Brasil experimenta a introdução de novas tecnologias direcionando as empresas a se adaptarem as mudanças ocorridas e buscar competitividade nesse novo contexto, objetivando produzir mais com melhor desempenho., o que era conhecido até o momento passa a ser obsoleto, necessitando cada vez mais que a mão de obra se qualifique e se torne polivalente para os mais diversos setores da economia. Assim, vários trabalhadores perderam seus empregos gerando um crescimento da taxa de desemprego não apresentando quedas significativas, pelo contrário, foram maiores em períodos de crise e instabilidade econômica, contra este fato, os profissionais buscaram se qualificar, gerando uma redução no número de analfabetos e aumento da mão de obra com Ensino Médio e Ensino Superior completo.

O trabalho tem como finalidade principal mensurar a geração de empregos por escolaridade do Paraná - Restante do Brasil. Posteriormente, pretende classificar os setores de acordo com a sua capacidade de geração de empregos dado o nível de 


\section{DEMANDA SETORIAL DE TRABALHO POR QUALIFICAÇÃO NO PARANÁ}

escolaridade identificando quais setores apontam o maior efeito transbordamento e quais possuem participação percentual mais significante em cada nível educacional, com isso será possível apontar os setores-chave para o desenvolvimento econômico e social das regiões estudadas.

A pesquisa recai sobre estado do Paraná por poucos estudos com essa finalidade, por ser atual mensurando o ano 2013 decorrendo do procedimento metodológico que utiliza uma matriz insumo-produto mais recente, se destaca ainda por apresentar mais setores na matriz com um total de 55 e se diferencia das pesquisas já existentes, como de Kureski (2012) e Perobelli (2016), por fazer a análise inter-regional. O resultado possibilita traçar estratégias de desenvolvimento educacional para o crescimento econômico do estado do Paraná, bem como para o restante do país.

A metodologia proposta utilizou o sistema de insumo-produto inter-regional. Com os resultados será possível estimar para cada setor da economia os geradores (total, direto ou indireto) a partir dos coeficientes técnicos diretos e a inversa da matriz de Leontief inter-regional, e no caso específico da matriz estadual destaca-se a importância do efeito transbordamento. Os dados de emprego por qualificação foram classificados com base na Relação Anual de Informações Sociais (RAIS) do Ministério do Trabalho (MTE) do ano de 2013 e os setores foram agregados em 55 para se equiparar a matriz utilizada. Ainda o trabalho utiliza a metodologia de Guilhoto et al (2010), com dados da matriz desse mesmo ano.

O estudo está dividido em cinco secções, além dessa introdução. Na segunda secção analisa as perspectivas do mercado de trabalho e qualificação para o Paraná e o restante do Brasil, bem como os estudos empíricos que já abordaram este tema, na terceira seção está a metodologia da pesquisa e a base de dados, a quarta secção discute os resultados da pesquisa. Por fim, a quinta expõe as considerações finais.

\section{MERCADO DE TRABALHO E QUALIFICAÇÃO: EVOLUÇÃO DO PERFIL DOS TRABALHADORES E ESTUDOS EMPÍRICOS}

Dados apresentados no relatório do Programa das Nações Unidas para os Desenvolvimentos (PNUD, 2013) para a América Latina, mostram que o Brasil está em terceiro lugar no que diz respeito ao pior índice de desigualdade do mundo e que mesmo aumentando os investimentos sociais nos últimos dez anos o país apresenta pouca mudança educacional e social entre as gerações. O relatório aponta que uma geração replica 55\% do nível de educação da geração anterior e 58\% da desigualdade social são mantidos dos seus ancestrais. Assim, o estudo conclui que o cenário educacional do país não mude no curto prazo, acarretando em poucas alterações econômicas e sociais.

Mota et al (2014) afirmam que as soluções para diminuir as desigualdades são voltadas aos problemas de diferença de renda, pobreza, condições precárias, entre outros fatores que se associa a dificuldade em melhorar a educação. No mesmo caminho podem-se citar os trabalhos de Barros, Camargo e Mendonça (1997); Ferreira e Veloso (2005) e Ramos e Mendonça (2005), que destacam o papel dos fatores educacionais, que estão relacionados a diferenças de renda, pobreza, condições de vida, tamanho das famílias, aumento da produtividade da mão de obra e melhores oportunidades no mercado de trabalho.

É importante estabelecer uma relação entre o nível de educação, mão de obra e emprego disponível. Letelier (1999) estabelece um debate acerca da oferta de mão de obra qualificada e as demandas do mercado de trabalho, destacando os desequilíbrios nos níveis de escolaridade da população economicamente ativa, que suporta o choque 


\section{DEMANDA SETORIAL DE TRABALHO POR QUALIFICAÇÃO NO PARANÁ}

entre os processos de reestruturação do trabalho e da economia para atender as atividades dos ramos produtivos, estão diretamente ligados à desigualdade salarial.

Como apresentado por Kon (2006), a maneira como são distribuídas as ocupações no mercado de trabalho brasileiro é resultado dos impactos de problemas conjunturais macro e microeconômicos que levam a novas necessidades e exigências para a contratação de mão de obra, pois os processos produtivos e organizacionais mudaram tendo em vista o aumento da competitividade entre as economias mundiais. Nessa linha, a autora destaca que na década de 1990 com a modernização industrial, observa-se a volta do crescimento na produtividade particularmente no setor primário, onde a taxa de crescimento da população ocupada aumentou $2 \%$ contrariando a tendência de queda apresentada até então.

Em relação ao cenário conjuntural e estrutural do mercado de trabalho no Brasil, é possível observar a evolução da taxa de desemprego a partir de 1994 (início do Plano Real) no Gráfico 1, nota-se uma taxa crescente, atingindo seu ápice em meados de 1999 com uma taxa de $10,4 \%$. No período de 2000 a taxa de desemprego apresentou uma queda chegando $7,8 \%$, até o início de 2005 a média da taxa de desemprego variou alcançando $10,2 \%$ neste ano, após esta fase inicia-se uma pequena recuperação entre 2008 a 2012 com taxas de 7,8\% a 6,7\%. Em 2015 volta a apresentar um crescimento do desemprego finalizando o ano com taxas de 7,5\%. Porém, com a crise política e econômica no país em meados de 2016 para 2017, essas taxas foram ainda maiores alcançando $11,4 \%$ e $12,7 \%$ respectivamente, percentuais maiores que no início do plano real.

Gráfico 1: Evolução da taxa de desemprego (\%) no Brasil 1994 - 2017

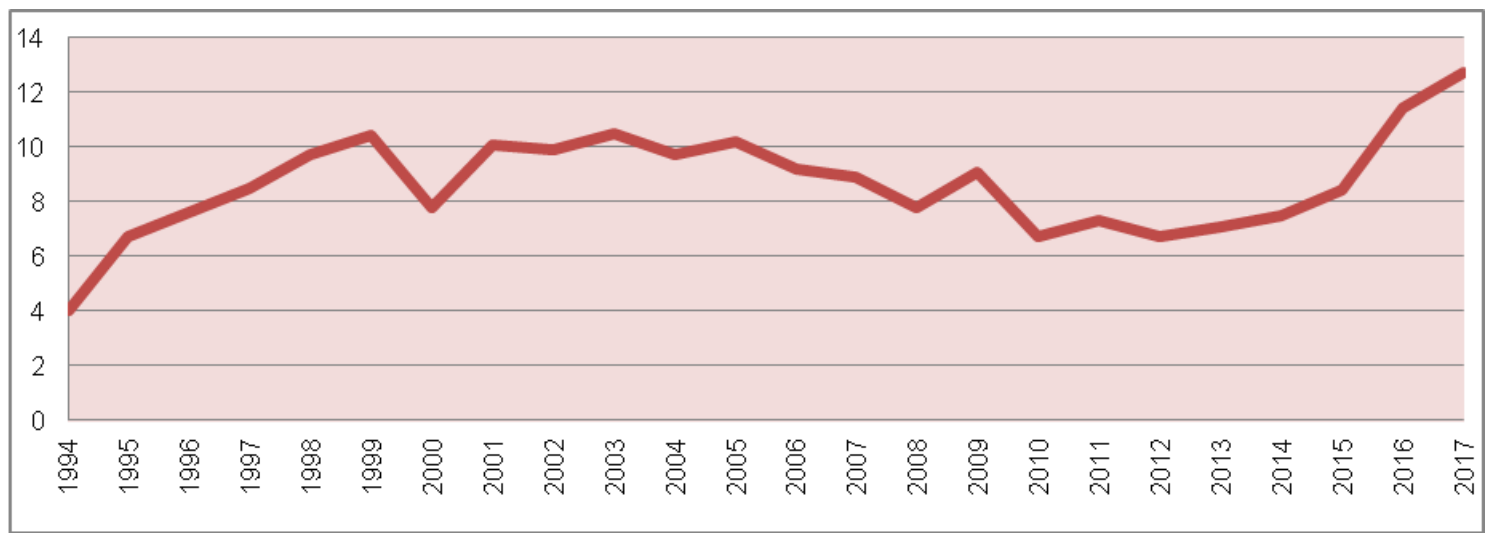

Fonte: o próprio autor com base nos dados do IPEADATA (2018)

Manfredi (1998) observou que a qualificação profissional teve que começar a mudar de quadro a partir de 1995, pois até então, a maioria das contratações eram voltadas a baixa qualificação. Mesmo que a ideia de competência ${ }^{1}$ já fosse conhecida no Brasil, quando a economia apresentou altas taxas de desemprego ela começa a ser utilizada com mais ação. A aptidão para saber dominar situações complexas na atuação do trabalho e transmitir as experiências que foram adquiridas anteriormente em outras situações, assim como a capacidade de resolver problemas com rapidez, surgem no

\footnotetext{
${ }^{1}$ Estoque de conhecimento e habilidades, capacidade de agir, intervir, decidir em situações nem sempre previstas ou previsíveis (MANFREDI, 1998).
} 


\section{DEMANDA SETORIAL DE TRABALHO POR QUALIFICAÇÃO NO PARANÁ}

exercício da capacidade profissional acarretando na busca de qualificação por parte dos profissionais, fato observado no Gráfico 2 a seguir.

Gráfico 2: Evolução da Qualificação da Mão de Obra no Brasil 1994 - 2016

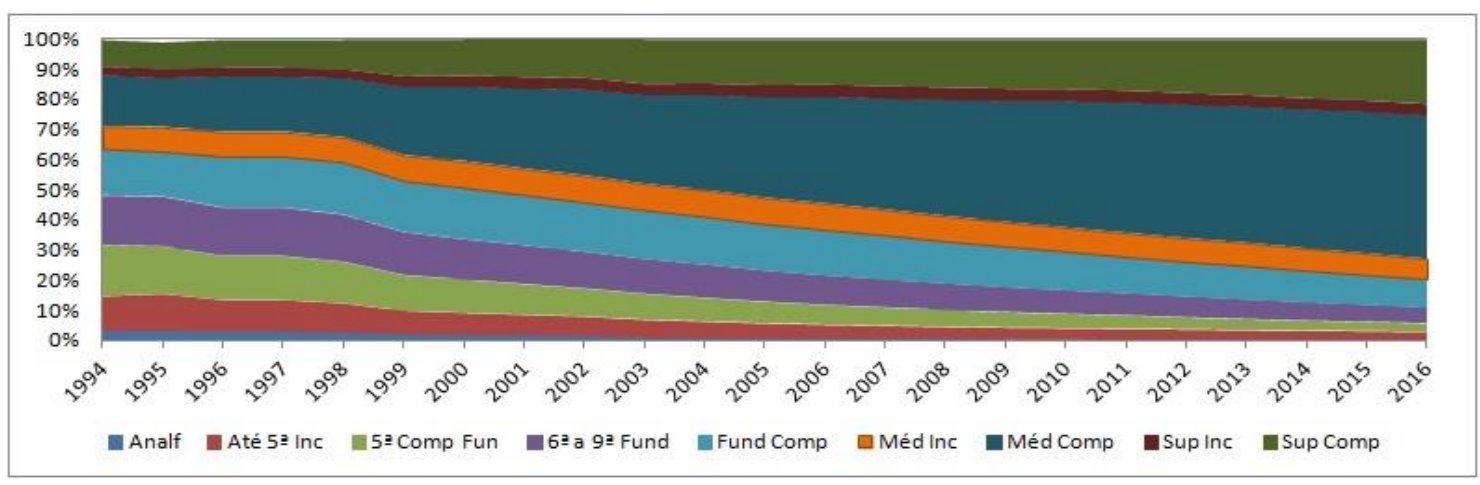

Fonte: o próprio autor com base nos dados RAIS-CAGED (2016)

Partindo do princípio que o presente trabalho busca estimar a geração de emprego por escolaridade para o estado Paraná, acarretou na necessidade de conhecer a evolução da taxa de desemprego e da qualificação para o estado. O Gráfico 3 mostra que após o início do Plano Real o estado do Paraná apresentou uma crescente taxa de desemprego, o que em 1994 apontava 5,1\% chegou a 8,4 em 1998, taxas bem próximas quando comparadas a todo o Brasil. No inicio dos anos 2000 estas taxas apresentaram quedas, com sua menor taxa no ano de $2008 \mathrm{com} \mathrm{5,0 \% ,} \mathrm{como} \mathrm{este} \mathrm{ano} \mathrm{foi} \mathrm{marcado} \mathrm{pela}$ crise internacional, o mercado reagiu de forma contracionista, acarretando novamente na queda do emprego, chegando em 2010 com 6,7\% de desempregados no estado do Paraná.

O estado alcançou sua menor taxa de desemprego em 2013 com 4,5\% de desempregados. Como em 2014 a economia nacional começa a sentir os primeiros impactos da crise política e financeira estaria por vir, a taxa de desemprego no Paraná aponta crescimento em 2014 com 4,6\% e alcança em 2017 8,3\% de taxa de desemprego, dados este quando comparados ao restante do Brasil são menores, pois o país alcançou $12,7 \%$ no mesmo ano.

Gráfico 3: Evolução da taxa de desemprego (\%) no Paraná 1994 - 2017

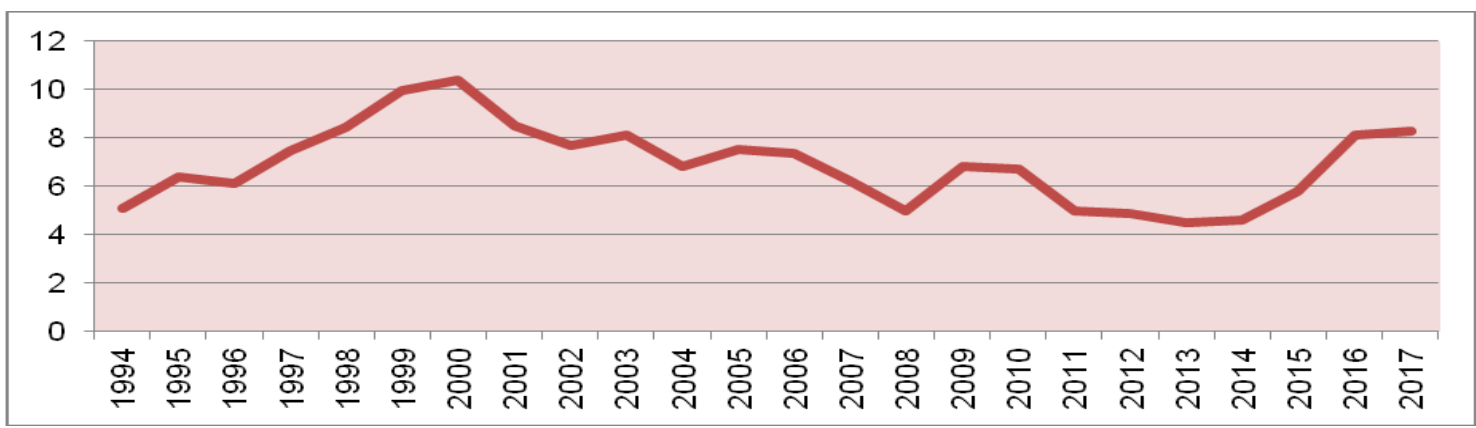

Fonte: o próprio autor com base nos dados do IPEADATA (2018)

A crescente taxa de desemprego levou ao aumento da qualificação profissional, apontados no Gráfico 4. Assim como ocorreu em todo o Brasil, o estado Paraná apresentou uma queda no número de analfabetos, em 1994 era de $2 \%$ alcançando $1 \%$ 


\section{DEMANDA SETORIAL DE TRABALHO POR QUALIFICAÇÃO NO PARANÁ}

em 2000, quando se fala em mão de obra com Ensino Médio Completo, o estado do Paraná apresentou um crescimento muito parecido com todo o País, o que correspondia a 17\% em 1994 alcançou uma taxa de 22\% em 2000. Da mesma forma, os trabalhadores qualificados com o Ensino Superior completo eram de 11\% em 1994 e mantendo a mesma taxa no ano 2000, quando analisa estes dados comparando ao País o estado se comportou da mesma forma.

Gráfico 4: Evolução da Qualificação da Mão de Obra no Paraná 1994 - 2016

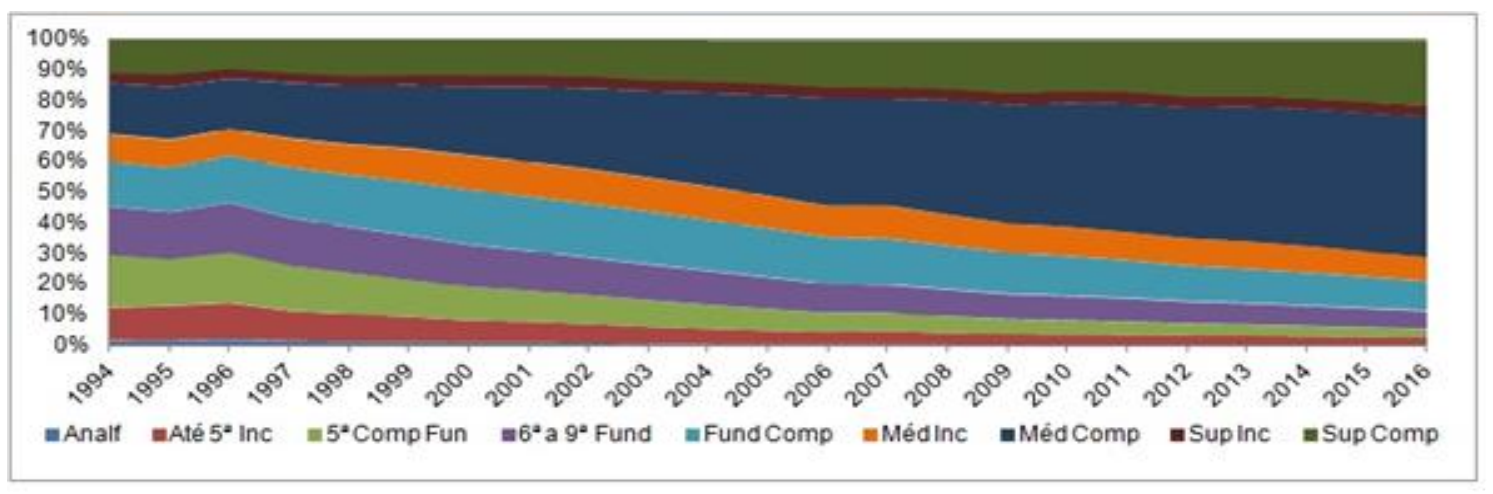

Fonte: o próprio autor com base nos dados do RAIS-CAGED (2016)

Os estudos para geração de empregos e qualificação também utilizam a metodologia insumo-produto. Kureski et al (2012) estimou a matriz insumo-produto para analisar o volume de emprego e renda direto, indireto e induzido gerados no estado do Paraná (regional), por nível de educação. Na matriz insumo-produto, o autor dividiu as contas do valor adicionado apresentando os números de empregos e renda por atividade econômica, contudo os dados não estão disponíveis para os níveis de educação, utilizando os dados da PNAD para o ano de 2006 (disponível no momento da análise). $\mathrm{O}$ autor dividiu o nível de educação através de anos de estudo da seguinte forma: sem instrução e menos de 1 ano, 1 e 2 anos, 3 e 4 anos, 5 e 6 anos, 7 e 8 anos, 11 e 12 anos, 13 e 14 anos, 15 anos de instrução, não declarados e não determinados. A agregação foi reduzida de 49 para 42, pois o número de atividade da matriz insumoproduto devia ser compatível com o nível de educação por anos de instrução.

Kureski et al (2012) demonstrou com os resultados que os multiplicadores de emprego são maiores nas atividades de outros serviços, chegando a 22,47\% para trabalhadores com 11 e 12 anos de estudo, refletindo na melhor distribuição de renda entre trabalho e capital. Assim os maiores multiplicadores de renda encontrados na pesquisa foram para o setor de educação mercantil com $60,75 \%$ para trabalhadores com 11 e 15 anos de estudo, pois a grande parcela do valor de produção é composta pelos rendimentos dos empregos. $\mathrm{O}$ autor detectou que no período analisado, o setor de confecções se destacou por apresentar maiores incrementos em empregos, nos termos absolutos e relativos. Desde 1995 a geração de empregos neste período cresceu 200,1\% até 2005 e um incremento de 37,3 mil postos de trabalho no estado do Paraná, ressaltando que neste setor o nível de emprego ocorre de modo contínuo.

Perobelli et al (2016) também com a metodologia de insumo-produto, analisou os empregos gerados dado o nível de escolaridade dos trabalhadores em setores para economia brasileira (nacional) no período de 1990 a 2005, através dos dados da população economicamente ativa dividida em cinco grupos de escolaridade: analfabeto, 1 a 3 anos de estudo, 4 a 7 anos, de 8 a 11 anos e com mais de 12 anos de estudos, 
dados estes extraídos da RAIS e distribuída para 26 setores. A matriz insumo-produto utilizada para pesquisa foi a disponível no IBGE, agregada para 21 setores a fim de igualar as matrizes disponíveis para o período. $\mathrm{O}$ autor pode concluir que os multiplicadores com a maior contribuição relativa, em todos os setores, são para os agentes com maior qualificação (multiplicadores de 8 a 11 anos de estudo). Segundo o autor, estes resultados são positivos, pois quando os multiplicadores apontam qualificações mais altas indicam uma agregação maior de tecnologia nos processos de produção, para tanto a capacidade de concorrência e o potencial oculto para o crescimento deste fenômeno permanece em alta.

A análise setorial realizada no trabalho de Perobelli et al (2016) detectou com os multiplicadores uma evolução na participação dos setores de serviços, que concentra a mão de obra qualificada e agricultura que concentra a mão de obra menos qualificada ou sem nenhuma instrução, necessitando de políticas voltadas a estes setores, que geraria um ganho de empregos diretos e indiretos.

\section{REFERENCIAL TEÓRICO E METODOLOGIA DE ESTIMAÇÃO}

O método de matriz insumo-produto foi originalmente desenvolvido para analisar e avaliar as relações entre os diversos setores produtivos e de consumo de uma economia nacional. Contudo, pode ser aplicado ao estudo de sistemas econômicos menores, como estados, municípios ou conjunto de municípios (LEONTIEF, 1988, p. 73). Neste caso trabalha-se com o modelo inter-regional, onde o Quadro 3 apresenta de forma esquemática, as relações dentro do sistema de insumo-produto inter-regional para duas regiões, a saber: (E) Estado e (RBr) Restante do País.

Quadro 3 - Relações de Insumo-produto no sistema inter-regional

\begin{tabular}{|c|c|c|c|c|c|}
\hline & Setores-Estado E & $\begin{array}{c}\text { Setores-Restante } \\
\text { do Brasil } \mathrm{RBr}\end{array}$ & $\begin{array}{l}\text { Demand } \\
\text { a Final E }\end{array}$ & $\begin{array}{l}\text { Demand } \\
\text { a Final } \\
\text { RBr }\end{array}$ & $\begin{array}{c}\text { Produção } \\
\text { Total }\end{array}$ \\
\hline $\begin{array}{l}\text { Setores- } \\
\text { Estado E }\end{array}$ & $\begin{array}{c}\text { Insumos } \\
\text { Intermediários } \\
Z^{E E}\end{array}$ & $\begin{array}{c}\text { Insumos } \\
\text { Intermediários } \\
Z^{E B R r}\end{array}$ & Y EE & Y ERBr & X E \\
\hline \multirow[t]{4}{*}{$\begin{array}{c}\text { Setores - } \\
\text { Restante } \\
\text { do Brasil } \\
\text { RBRr }\end{array}$} & $\begin{array}{c}\text { Insumos } \\
\text { Intermediários } \\
Z^{B R r E}\end{array}$ & $\begin{array}{c}\text { Insumos } \\
\text { Intermediários } \\
Z^{R B r B R r}\end{array}$ & Y RBrE & $\begin{array}{c}\mathrm{Y} \\
\mathrm{RBrRBr}\end{array}$ & $\mathrm{X} \mathrm{RBr}$ \\
\hline & $\begin{array}{c}\text { Importação } \\
\text { Restante Mundo } \\
\text { (IME) }\end{array}$ & $\begin{array}{c}\text { Importação } \\
\text { Restante Mundo } \\
\text { (IMRBr) }\end{array}$ & & & \\
\hline & $\begin{array}{l}\text { Imposto Indireto } \\
\text { Líquido (IILE) }\end{array}$ & $\begin{array}{l}\text { Imposto Indireto } \\
\text { Líquido (IILRBr) }\end{array}$ & & & \\
\hline & $\begin{array}{c}\text { Valor Adicionado } \\
\text { E }\end{array}$ & $\begin{array}{c}\text { Valor Adicionado } \\
\text { RBR }\end{array}$ & & & \\
\hline
\end{tabular}


DEMANDA SETORIAL DE TRABALHO POR QUALIFICAÇÃO NO PARANÁ

\begin{tabular}{|c|c|}
\hline $\begin{array}{c}\text { Produção Total } \\
\text { Região E }\end{array}$ & $\begin{array}{c}\text { Produção Total } \\
\text { Região } \mathrm{RBr}\end{array}$ \\
\hline Emprego Total E & $\begin{array}{c}\text { Emprego Total } \\
\mathrm{RBr}\end{array}$ \\
\hline $\begin{array}{c}\text { Emprego Ensino } \\
\text { Fundamental E }\end{array}$ & $\begin{array}{c}\text { Emprego Ensino } \\
\text { Fundamental } \mathrm{RBr}\end{array}$ \\
\hline $\begin{array}{c}\text { Emprego Ensino } \\
\text { Médio E }\end{array}$ & $\begin{array}{c}\text { Emprego Ensino } \\
\text { Médio } \mathrm{RBr}\end{array}$ \\
\hline $\begin{array}{c}\text { Emprego Ensino } \\
\text { Superior E }\end{array}$ & $\begin{array}{c}\text { Emprego Ensino } \\
\text { Superior } \mathrm{RBr}\end{array}$ \\
\hline
\end{tabular}

Fonte: Adaptado de Richardson (1978)

O modelo inter-regional de insumo-produto, também chamado de "modelo Isard" devido à aplicação de Isard (1951), requer grande massa de dados reais ou estimados, principalmente quanto às informações sobre fluxos intersetoriais e interregionais. Complementando o sistema regional, o sistema inter-regional mostra as relações de troca entre as regiões, exportações e importações, que são expressas por meio do fluxo de bens e serviços que se destinam tanto ao consumo intermediário quanto à demanda final. De forma sintética ${ }^{2}$, apresentando apenas a relação Estado Restante do País, pode-se apresentar o modelo a partir do exemplo hipotético dos fluxos intersetoriais e inter-regionais de bens para o Estado (E) e Restante do Brasil (RBr), com $n$ setores, onde $Z^{E E}$ é o fluxo monetário do setor $i$ para o setor $j$ do próprio Estado (E), $Z^{R B r R B r}$ é o fluxo monetário do setor $i$ para o setor $j$ do Restante do Brasil (RBr) para ele mesmo, $Z^{R B r E}$ é o fluxo monetário do setor $i$ do Restante do Brasil (RBr) para o setor $j$ do Estado (E) e $Z^{E R B r}$ é o fluxo monetário do setor $i$ do Estado (E) para o setor $j$ do Restante do Brasil (RBr) (Guilhoto, 2011). Na forma matricial, esses fluxos seriam representados por:

$$
Z=\left[\begin{array}{cc}
Z^{E E} & Z^{E R B r} \\
Z^{R B r E} & Z^{R B r R B r}
\end{array}\right]
$$

em que $Z^{E E}$ e $Z^{R B r R B r}$, representam matrizes dos fluxos monetários intra-regionais, e $Z^{E R B r}$ e $Z^{R B r E}$, representam matrizes dos fluxos monetários inter-regionais. As demais demandas finais, $Y^{R B r}$ e $Y^{E}$, podem ser obtidas similarmente (conforme equação 4). Portanto, de acordo com $A=Z(\hat{X})^{-1}$, constrói-se a matriz para os $n$ setores, em que $A$ representa a matriz de coeficientes técnicos intra-regionais de produção (equação 2 ), $Z$ é o valor dos insumos intermediários (equação 1) e $X$ é o valor bruto de produção (equação 3).

$$
\begin{gathered}
A=\left[\begin{array}{cc}
A^{E E} & A^{E R B r} \\
A^{R B r E} & A^{R B r R B r}
\end{array}\right] \\
X=\left[\begin{array}{c}
X^{E} \\
X^{R B r}
\end{array}\right]
\end{gathered}
$$

\footnotetext{
${ }^{2} \mathrm{O}$ procedimento completo, calculado a partir de dados primários pode ser visto em Guilhoto (2011, p. 34-35).
} 
DEMANDA SETORIAL DE TRABALHO POR QUALIFICAÇÃO NO PARANÁ

$$
Y=\left[\begin{array}{c}
Y^{E} \\
Y^{R B r}
\end{array}\right]
$$

O sistema inter-regional de insumo-produto completo é representado por:

$$
(I-A) X=Y
$$

e as matrizes podem ser dispostas da seguinte forma:

$$
\left\{\left[\begin{array}{ll}
1 & 0 \\
0 & 1
\end{array}\right]-\left[\begin{array}{cc}
A^{E E} & A^{E R B r} \\
A^{R B r E} & A^{R B r R B r}
\end{array}\right]\right\}\left[\begin{array}{c}
X^{E} \\
X^{R B r}
\end{array}\right]=\left[\begin{array}{c}
Y^{E} \\
Y^{R B r}
\end{array}\right]
$$

Efetuando estas operações, obtém-se o modelo básico necessário à análise inter-regional proposta por Isard (1951), resultando no sistema de Leontief inter-regional da forma:

$$
X=(I-A)^{-1} Y
$$

o qual pode ser escrito como:

$$
\left[\begin{array}{c}
X^{E} \\
X^{R B r}
\end{array}\right]=\left[\begin{array}{cc}
B^{E E} & B^{E R B r} \\
B^{R B r E} & B^{R B r R B r}
\end{array}\right]\left[\begin{array}{c}
Y^{E} \\
Y^{R B r}
\end{array}\right]
$$

Assim, como na análise nacional é possível estimar para cada setor da economia os multiplicadores e geradores (total, direto ou indireto) a partir dos coeficientes técnicos diretos e da matriz inversa de Leontief inter-regional (Miller e Blair, 2009). No caso específico da matriz estadual, destaca-se a importância do efeito transbordamento. Para estimar o efeito transbordamento no emprego, primeiramente, deve-se calcular o gerador (9), o qual permite analisar o impacto de uma variação na demanda final de determinado setor sobre a variável econômica de interesse (Miller e Blair, 2009). O valor calculado representa o valor total de produção de toda a economia que é acionado para atender a variação de uma unidade na demanda final do setor $\mathrm{j}$. $\mathrm{O}$ efeito transbordamento mostra como o aumento da produção setorial em dada região impacta a produção dos setores de outra região.

Em relação à base de dados, destaca-se que o trabalho tem como referência a metodologia de Guilhoto et al (2010), com dados de emprego por qualificação da Relação Anual de Informações Sociais (RAIS) do Ministério do Trabalho (MTE) do ano de 2013. O ano de 2013 foi escolhido por ser a metodologia da matriz insumoproduto mais recente disponível, acarretando em um trabalho atualizado, bem como, a escolha do Paraná foi definida pela carência de estudos voltados ao estado mensurando o emprego dado à qualificação do profissional.

O trabalho foi agregado em 56 setores, para se equiparar ao número de setores da matriz de insumo-produto estimada por Guilhoto et al (2010), porém surgiu a necessidade de retirar o setor extração de minerais, pela inexistência deste setor no estado do Paraná totalizando 55 setores, assim a Tabela 1 apresenta os setores classificados e o total de empregos gerados.

Os níveis de qualificação da seguinte forma: Ensino Fundamental (analfabeto, completo e incompleto) definido como fundamental 1; Ensino Médio (completo e incompleto) como fundamental 2 e Ensino Superior (completo, incompleto, pósgraduação, mestrado e doutorado) incluído no fundamental 3. Para melhor compreensão dos níveis de qualificação agregados são necessárias as definições utilizadas na metodologia da pesquisa, dessa forma, analfabetos são os que não sabem ler e escrever, 


\section{DEMANDA SETORIAL DE TRABALHO POR QUALIFICAÇÃO NO PARANÁ}

para considerar que o indivíduo possua o ensino fundamental 1 é necessário que tenha o fundamental completo até o ensino médio incompleto. Agora para definir o indivíduo dentro do fundamental 2 ele deve possuir o ensino médio completo ou até o ensino superior incompleto e para possuir a qualificação fundamental 3 o profissional deve possuir o superior completo com ou sem a especialização.

A partir dos coeficientes diretos e da matriz inversa de Leontief é possível estimar, para cada setor da economia, o quanto é gerado direta e indiretamente de empregos no total e por escolaridade para cada unidade monetária produzida para a demanda final (Miller e Blair, 2009), ou seja:

$$
G V_{j}=\sum_{i=1}^{n} b_{i j} v_{i}
$$

em que

$G V_{j}$ é o impacto total, direto e indireto, sobre a variável em questão; $b_{i j}$ é o ij-ésimo elemento da matriz inversa de Leontief e

$v_{i}$ é o coeficiente direto da variável emprego (quociente entre os tipos de emprego e o valor bruto de produção).

Onde, $G V_{j}$ é o gerador de produção do j-ésimo setor e as outras variáveis são definidas segundo o expresso anteriormente. Quando o efeito gerador se restringe somente à demanda de insumos intermediários (foco deste trabalho), estes geradores são chamados "do tipo I". Porém, quando a demanda das famílias é endogenizada no sistema, levando-se em consideração o efeito induzido, estes geradores recebem a denominação "do tipo II".

Os geradores tipo I e tipo II serão individualizados para cada tipo de emprego em níveis de qualificação: Emprego Total E; Emprego Ensino Fundamental E; Emprego Ensino Médio E; e Emprego Ensino Superior E.

Suponha que a demanda de um determinado produto aumente, como por exemplo, a demanda por automóveis fabricados no Brasil. Este crescimento irá sinalizar para os produtores de automóveis aumentarem sua produção e ao mesmo tempo as empresas de autopeças irão intensificar sua produção de pneus, vidros, transmissores, motores, etc. isso acontece simultaneamente também para os fornecedores da companhia de peças, esse processo e conhecido como multiplicador de produção. Vale ressaltar que alguns setores da economia estão envolvidos mais ativamente na compra direta e indireta - de que outros setores, então o efeito gerado pelo crescimento da demanda de determinado produto causa diferentes impactos na economia.

A divisão dos geradores pelo respectivo coeficiente direto gera os multiplicadores, que indicam quanto é gerado, direta e indiretamente, de emprego, importações, impostos, ou qualquer outra variável para cada unidade produzida para demanda final. Em outras palavras, o multiplicador do i-ésimo setor seria dado então por:

$$
M V_{i}=\frac{G V_{i}}{v_{i}}
$$

em que $M V_{i}$ representaria o multiplicador da variável em questão e as outras variáveis são definidas conforme feito anteriormente.

Por sua vez, o multiplicador de produção que indica o quanto se produz para cada unidade monetária gasta no consumo final é definido como: 


\section{DEMANDA SETORIAL DE TRABALHO POR QUALIFICAÇÃO NO PARANÁ}

$$
M P_{j}=\sum_{i=1}^{n} b_{i j}
$$

em que $M P_{j}$ é o multiplicador de produção do j-ésimo setor da matriz de Leontief e as outras variáveis são definidas segundo o expresso anteriormente. $M P_{j}$ é representado pelo impacto total, direto e indireto pela variável em questão, nota-se que o fator inicial é a variação da demanda final do setor.

Para estimar o efeito de transbordamento dos multiplicadores de produção é necessário inicialmente, calcular o multiplicador (10), que irá permitir analisar qual o impacto na demanda final de um setor determinado sobre a variável econômica de interesse (Miller e Blair, 2009). O resultado irá representar o valor total de produção de toda economia, que é demandado para atender a variação de uma unidade na demanda final do setor $j$.

A partir do resultado obtido no multiplicador, o efeito transbordamento de uma região em relação à outra, é estimado pela diferença entre os multiplicadores dessas, que pode ser apresentado tanto em termos absolutos quanto em valores percentuais. $\mathrm{O}$ efeito transbordamento busca demonstrar como o aumento da produção setorial em dada região, impacta na produção dos setores de outras regiões.

O efeito transbordamento foi estipulado neste trabalho para o Estado do Paraná restante do Brasil, analisando os efeitos direto, indireto e induzido encontrado nos multiplicadores. Para tanto a análise foi feita individualmente para cada nível educacional, conforme suas agregações: Emprego Total E; Emprego Ensino Fundamental E; Emprego Ensino Médio E; e Emprego Ensino Superior E.

\section{RESULTADOS E DISCUSSÃO}

Verificando a tendência de crescimento nas taxas educacionais versus o aumento da taxa de desemprego, é possível destacar os oito setores (1/7 dos dados (volume) disponíveis) que mais geraram empregos formais no estado do Paraná (intrarregional) conforme o nível de qualificação da mão de obra, dado a variação de um milhão de reais na demanda final em 2013.

Os setores com maiores geradores de emprego, para o nível Fundamental têmse: Produção florestal; pesca e aquicultura (2); Extração mineral metálicos (4); Confecção de artefatos do vestuário e acessórios (9); Fabricação de outros equipamentos de transporte, exceto veículos automotores (25); Alojamento (37); Alimentação (38); Outras atividades administrativas e serviços complementares (49) e Atividades de vigilância, segurança e investigação (50).

Tratando-se do nível de qualificação Ensino Médio os oito setores que mais geraram empregos no estado do Paraná, sendo eles: Confecção de artefatos do vestuário e acessórios (9); Comércio por atacado e a varejo, exceto veículos automotores (32); Alojamento (37); Alimentação (38); Outras atividades administrativas e serviços complementares (49); Atividades de vigilância, segurança e investigação (50); Educação privada (52) e Saúde privada (53). Com nível Superior de ensino no ano de 2013, compreendendo os oito maiores setores: Edição e edição integrada à impressão (39); Desenvolvimento de sistemas e outros serviços de informação (42); Intermediação financeira, seguros e previdência complementar (43); Outras atividades profissionais, científicas e técnicas (47); Administração pública, defesa e seguridade social (51); Educação privada (52); Saúde privada (53) e Organizações associativas e outros serviços pessoais $(55)$. 


\section{DEMANDA SETORIAL DE TRABALHO POR QUALIFICAÇÃO NO PARANÁ}

Dando continuidade, foram identificados quantos empregos gerados para o estado do Paraná e o restante do Brasil dado a variação de um milhão de reais na demanda final para o ano de 2013 (matriz insumo-produto atualizada para este ano). Com isso, o Ensino Fundamental, foram destacados na Tabela 3 os oito setores que mais geraram empregos diretos no estado do Paraná, sendo eles: Produção florestal; pesca e aquicultura (2); Extração mineral metálicos (4); Confecção de artefatos do vestuário e acessórios (9); Fabricação de outros equipamentos de transporte, exceto veículos automotores (25); Alojamento (37); Alimentação (38); Outras atividades administrativas e serviços complementares (49) e Atividades de vigilância, segurança e investigação (50). O gerador de produção indireto de Ensino Fundamental para o estado do Paraná destaca os setores: Extração mineral metálicos (4); Fabricação de bebidas (6); Fabricação de produtos do fumo (7); Fabricação de produtos de minerais não metálicos (18); Fabricação de outros equipamentos de transporte, exceto veículos automotores (25); Construção (30); Transporte aéreo (35) e Telecomunicações (41). Quando se trada de empregos gerados indiretamente à produção, o setor com maior gerador foi o de Fabricação de outros equipamentos de transporte, exceto veículos automotores (25) com 1,5 empregos, este setor compreende atividades de construção de embarcações e estruturas flutuantes, veículos ferroviários, aeronaves, motocicletas, bicicletas e outros meios de transporte, bem como veículos militares e de combate, cadeira de rodas e veículos semelhantes para deficientes físicos e fabricação de peças e acessórios para veículos produzidos na região.

O efeito induzido apresenta os empregos que são gerados através do uso formal da renda das famílias, no estado do Paraná em 2013 os setores que mais empregos geraram para o efeito induzido foram: Produção florestal; pesca e aquicultura (2); Água, esgoto e gestão de resíduos (29); Desenvolvimento de sistemas e outros serviços de informação (42); Atividades imobiliárias (44); Atividades jurídicas, contábeis, consultoria e sedes de empresas (45); Aluguéis não imobiliários e gestão de ativos de propriedade intelectual (48); Saúde privada (53) e Atividades artísticas, criativas e de espetáculos (54). Dentre estes setores destacados, o de Atividades imobiliárias (44) foi o que alcançou o maior gerador, com 0,24 empregos induzidos gerados. Assim, apontando os oito setores que mais empregaram indiretamente no país: Indústria de alimentos (5); Fabricação de produtos têxteis (8); Confecção de artefatos do vestuário e acessórios (9); Fabricação de calçados e de artefatos de couro (10); Fabricação de produtos da madeira (11); Fabricação de celulose, papel e produtos de papel (12); Fabricação de máquinas e equipamentos elétricos (22); Indústria automobilística e peças (24).

Já os setores que mais geraram empregos induzidos no país foram: Produção florestal; pesca e aquicultura (2); Água, esgoto e gestão de resíduos (29); Desenvolvimento de sistemas e outros serviços de informação (42); Intermediação financeira, seguros e previdência complementar (43); Atividades imobiliárias (44); Atividades jurídicas, contábeis, consultoria e sedes de empresas (45); Aluguéis não imobiliários e gestão de ativos de propriedade intelectual (48) e Atividades artísticas, criativas e de espetáculos (54). Dentre estes setores apresentados, o que mais gerou empregos induzidos no Restante do Brasil foi o de Atividades imobiliárias (44) com 3,2 empregos.

Os transbordamentos representam como o aumento de empregos nos setores do estado do Paraná impacta na geração de empregos nos setores do restante do Paraná. Com isso, destacam-se os oito setores com maior número de geradores em outras regiões do país com o nível de qualificação Ensino Fundamental: Refino de petróleo e coquerias e biocombustíveis (14); Indústria automobilística e peças (24); Energia 


\section{DEMANDA SETORIAL DE TRABALHO POR QUALIFICAÇÃO NO PARANÁ}

elétrica, gás natural e outras utilidades (28); Desenvolvimento de sistemas e outros serviços de informação (42); Intermediação financeira, seguros e previdência complementar (43); Atividades imobiliárias (44); Atividades jurídicas, contábeis, consultoria e sedes de empresas (45) e Atividades artísticas, criativas e de espetáculos (54). O setor que mais transbordou empregos para o Ensino Médio foi o de Atividades imobiliárias (44) com 84,4\%.

Analisando os dados da geração de empregos formais nos setores com mão de obra qualificada de nível Médio no estado do Paraná em 2013, é possível apontar os oito setores que mais empregaram diretamente: Confecção de artefatos do vestuário e acessórios (9); Comércio por atacado e a varejo, exceto veículos automotores (32); Alojamento (37); Alimentação (38); Outras atividades administrativas e serviços complementares (49); Atividades de vigilância, segurança e investigação (50); Educação privada (52) e Saúde privada (53). Quando se fala em empregos gerados indiretamente para Ensino Médio no Paraná em 2013, podem ser destacados os oito setores com maiores geradores: Extração mineral metálica (4); Fabricação de bebidas (6); Fabricação de outros equipamentos de transporte, exceto veículos automotores (25); Transporte aquaviário (34); Transporte aéreo (35); Telecomunicações (41); outras atividades profissionais, científicas e técnicas (47) e Saúde privada (53).

Pra geração de empregos induzidos pela renda das famílias, também analisados para o Ensino Médio destacam-se: Produção florestal; pesca e aquicultura (2); Água, esgoto e gestão de resíduos (29); Desenvolvimento de sistemas e outros serviços de informação (42); Atividades imobiliárias (44); Atividades jurídicas, contábeis, consultoria e sedes de empresas (45); Aluguéis não imobiliários e gestão de ativos de propriedade intelectual (48); Saúde privada (53) e Atividades artísticas, criativas e de espetáculos (54). Dessa forma os setores que mais geraram empregos indiretos à cadeia produtiva no país para o ano de 2013 foram: Fabricação de produtos têxteis (8); Confecção de artefatos do vestuário e acessórios (9); Fabricação de calçados e de artefatos de couro (10); Fabricação de celulose, papel e produtos de papel (12); Refino de petróleo e coquerias e biocombustíveis (14); Fabricação de máquinas e equipamentos elétricos (22); Fabricação de máquinas e equipamentos mecânicos (23) e Indústria automobilística e peças (24).

Analisando os empregos induzidos no restante do Brasil, os setores que mais se destacaram foram: Produção florestal; pesca e aquicultura (2); Água, esgoto e gestão de resíduos (29); Desenvolvimento de sistemas e outros serviços de informação (42); Atividades imobiliárias (44); Aluguéis não imobiliários e gestão de ativos de propriedade intelectual (48); Saúde privada (53) e Atividades artísticas, criativas e de espetáculos (54). Concluindo as análises para o Ensino Médio, os setores que tiveram os maiores transbordamento do estado do Paraná para o restante do Brasil estão destacados na Tabela 4: Agropecuária (1); Produção florestal; pesca e aquicultura (2); Refino de petróleo e coquerias e biocombustíveis (14); Indústria automobilística e peças (24); Energia elétrica, gás natural e outras utilidades (28); Intermediação financeira, seguros e previdência complementar (43); Atividades imobiliárias (44) e Atividades artísticas, criativas e de espetáculos (54).

Os resultados referentes à geração de empregos formais com Ensino Superior nos setores do estado do Paraná dado a variação de um milhão de reais na demanda final no ano de 2013, destacando os oitos setores que mais geraram empregos diretos, sendo eles: Edição e edição integrada à impressão (39); Atividades de televisão, rádio, cinema e gravação/edição de som e imagem (40); Desenvolvimento de sistemas e outros serviços de informação (42); Intermediação financeira, seguros e previdência complementar (43); Outras atividades administrativas e serviços complementares (49); 


\section{DEMANDA SETORIAL DE TRABALHO POR QUALIFICAÇÃO NO PARANÁ}

Administração pública, defesa e seguridade social (51); Educação privada (52) e Saúde privada (53).

A geração de empregos indiretos no Paraná para o Ensino Superior destacam os setores com maiores geradores: Extração mineral metálicos (4); Transporte aquaviário (34); Atividades de televisão, rádio, cinema e gravação/edição de som e imagem (40); Telecomunicações (41); Intermediação financeira, seguros e previdência complementar (43); Atividades jurídicas, contábeis, consultoria e sedes de empresas (45); Outras atividades profissionais, científicas e técnicas (47) e Saúde privada (53). Para o efeito induzido, os setores com maior gerador foram: Produção florestal; pesca e aquicultura (2); Água, esgoto e gestão de resíduos (29); Comércio por atacado e a varejo, exceto veículos automotores (32); Alojamento (37); Desenvolvimento de sistemas e outros serviços de informação (42); Atividades jurídicas, contábeis, consultoria e sedes de empresas (45); Aluguéis não imobiliários e gestão de ativos de propriedade intelectual (48) e Atividades artísticas, criativas e de espetáculos (54).

Os setores com empregos indiretos com Ensino Superior gerados no restante do Brasil, podendo destacar os com maiores geradores: Indústria de alimentos (5); Fabricação de produtos da madeira (11); Fabricação de celulose, papel e produtos de papel (12); Refino de petróleo e coquerias e biocombustíveis (14); Fabricação de máquinas e equipamentos elétricos (22); Fabricação de máquinas e equipamentos mecânicos (23); Indústria automobilística e peças (24) e Transporte aquaviário. Os empregos induzidos gerados pela renda das famílias para o restante do Brasil possuem como estes setores que mais forneceram empregos: Água, esgoto e gestão de resíduos (29); Comércio por atacado e a varejo, exceto veículos automotores (32); Desenvolvimento de sistemas e outros serviços de informação (42); Intermediação financeira, seguros e previdência complementar (43); Atividades imobiliárias (44); Atividades jurídicas, contábeis, consultoria e sedes de empresas (45); Saúde privada (53) e Atividades artísticas, criativas e de espetáculos (54).

Os setores que mais geraram transbordamento de empregos do Paraná para o restante do Brasil foram: Agropecuária (1); Produção florestal; pesca e aquicultura (2); Fabricação de produtos da madeira (11); Refino de petróleo e coquerias e biocombustíveis (14); Indústria automobilística e peças (24); Manutenção, reparação e instalação de máquinas e equipamentos (27); Energia elétrica, gás natural e outras utilidades (28) e Atividades imobiliárias (44). Um fato que foge do comum está em que o setor de Intermediação Financeiro seguro e previdência complementar (43) não aparece como gerador de emprego direto, quando se aborda profissionais com mão de obra qualificada, mas aparece dentro da cadeia produtiva, gerando empregos indiretos.

O Gráfico 5 mostra os transbordamentos das escolaridades (ensino fundamental, ensino médio e o ensino superior) apontando os setores que enviam mão de obra do estado do Paraná para o restante do Brasil. É possível notar que o setor Agropecuária (1) possui um alto transbordamento para as qualificações, notando que quando se fala em mão de obra qualificada para este setor não está permanecendo no estado, mesmo sendo um setor de alta produtividade. O setor de Refino de petróleo e coqueiras e biocombustíveis (14) também apresentou um alto transbordamento para as qualificações mais altas, sendo um setor que exige a necessidade de absorver profissionais qualificados, bem como o setor de Energia elétrica, gás natural e outras utilidades (28) encontrando o mesmo caso. Como já foi visto ao longo da identificação dos dados o setor de Atividades Imobiliárias (44) transborda mão de obra qualificada com mais intensidade para o restante do Brasil. Para finalizar a análise, o setor de atividades artísticas, criativas e de espetáculos (54) com alto nível de transbordamento, este setor compreende as atividades de produção e promoção de artes cênicas, espetáculos e 


\section{DEMANDA SETORIAL DE TRABALHO POR QUALIFICAÇÃO NO PARANÁ}

atividades complementares. Compreende também as atividades de criação artística, como a de artistas plásticos (pintores, escultores) e escritores, bem como a gestão de espaços para artes cênicas, espetáculos e outras atividades artísticas.

Gráfico 5: Transbordamento de empregos Paraná-restante do Brasil para Ensino Fundamental, Ensino Médio e Ensino Superior

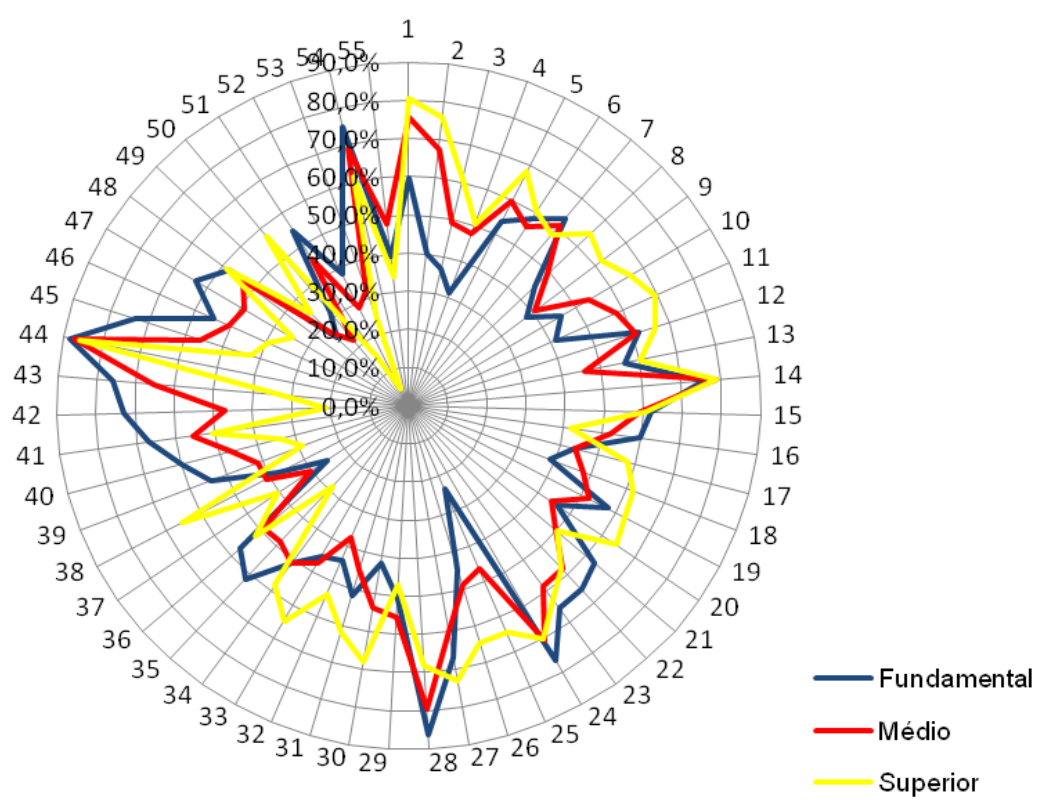

Fonte: o próprio autor com base nos dados RAIS/CAGED (2013).

O Gráfico 6 permite visualizar a participação dos geradores de empregos formais dado o nível de escolaridade dentro dos setores do Estado do Paraná no ano de 2013. Quando examinado para o Ensino Fundamental, os setores com maior participação na geração de empregos são: Produção florestal; pesca e aquicultura (2) com 66\%; Fabricação de Outro (25) com 64\% e os setores de Agropecuária (1) e Fabricação de calçados e de artefatos de couro (10) ambos com 56\% de participação na geração de empregos no estado do Paraná.

Da mesma forma para os profissionais com Ensino Médio, os setores com maior participação percentual na geração de empregos no Paraná foram: Atividades de vigilância, segurança e investigação (50) com 67\%; Fabricação de produtos de metal, exceto máquinas e equipamentos (20) com $61 \%$ e o setor de Fabricação de equipamentos de informática, produtos eletrônicos e ópticos (21) com 57\% de participação intrarregional.

Para a mão de obra com Ensino Superior, os setores com maior participação na geração de empregos foram: Administração pública, defesa e seguridade social (51) com 43\%; Educação privada (52) com 58\% de participação e os setores de Desenvolvimento de sistemas e outros serviços de informação (42), e o setor de Intermediação financeira, seguros e previdência complementar (43), ambos com aproximadamente $41 \%$ de participação.

Dessa forma, com a análise do Gráfico 6 é possível afirmar que no estado do Paraná os setores de atividades primárias, que abrangem atividades de exploração, produção e fabricação, empregam mais profissionais com mão de obra com o nível fundamental, sendo que os setores Agropecuária (1) e Produção florestal; pesca e aquicultura (2) estão entre os de maiores participações na geração de emprego do estado para o nível Ensino Fundamental. Bem como, a participação para mão de obra com 


\section{DEMANDA SETORIAL DE TRABALHO POR QUALIFICAÇÃO NO PARANÁ}

nível Ensino Médio compreende atividades de transformação contidas no setor secundário como o setor de Fabricação de produtos de metal, exceto máquinas e equipamentos (20) e Fabricação de equipamentos de informática, produtos eletrônicos e ópticos (21) com 57\% de participação.

Com a aplicação dos dados na metodologia apresentada, foram identificados alguns pontos relevantes na análise de geração de emprego no Estado do Paraná e Restante do Brasil com os níveis de qualificação agregados para o estudo em questão, assim, quanto a geração de empregos diretos para o Ensino fundamental o setor que mais empregou foi o de Alojamento (37), para o Ensino Médio foi o setor de Atividades de vigilância, segurança e investigação (50) e Ensino Superior o setor Educação Privada (52), nota-se que conforme a qualificação vai aumentando o setor que emprega diretamente também muda conforme o grau de especificação do trabalho.

Quando o estado do Paraná gera empregos indiretos no ano de 2013 o setor que mais emprega profissionais com Ensino Fundamental é o Fabricação de outros equipamentos de transporte, exceto veículos automotores (25), agora para Ensino Médio e Ensino Superior o setor que mais emprega é o de Outras atividades profissionais, científicas e técnicas. Quando comparado com o trabalho de Kureski et al (2006) os maiores multiplicadores de empregos com 11 e 12 anos de estudo (ensino médio) são para o setor de outros serviços e atividades mercantis, destacando que o trabalho do autor investigou o ano de 2006, nota-se uma mudança no mercado de trabalho paranaense que hoje emprega mais profissionais no setor de outras atividades profissionais, cientificas e técnicas.

Da mesma forma, quando as gerações de empregos são induzidas pela renda das famílias o setor de Atividades imobiliárias (44) é o que mais emprega profissionais com o Ensino Fundamental e o Ensino Médio. Mas para o Ensino Superior o setor destacado é o de Produção florestal; pesca e aquicultura (2).

As análises de geração de emprego no ano de 2013 recaíram para o Restante do Brasil, quando os efeitos deles são indiretos o setor que mais emprega mão de obra qualificada com o Ensino Fundamental e o Ensino médio é o de Confecção de artefatos do vestuário e acessórios (9), porém para o Ensino Superior o setor com maior gerador é a Indústria automobilística e peças (24), indicando que estes setores empregam dentro da cadeia produtiva. Comparando com o trabalho de Perobelli et al (2016) feito para o período de 1990 a 2005, para o Brasil, notou uma queda nos empregos gerados para profissionais com ensino mais elevado no setor de indústria mecânica e metalurgia, já para profissionais com o ensino fundamental, o autor detectou aumento na geração de empregos nos setores de alta tecnologia, como indústria química e eletrônica e comunicação), este trabalho demonstrou crescimento de emprego para as qualificações, mas os setores são diferentes do citado pelo autor.

Também para o restante do Brasil, quando os empregos gerados são induzidos pela renda das famílias o setor Atividades imobiliárias (44) foi o maior gerador de empregos para todos os níveis de educação: Ensino Fundamental, Ensino Médio e Ensino Superior, levando a crer que quando as famílias utilizam suas rendas impulsiona a geração de emprego no setor de Atividades imobiliárias (44), também causou impactos no efeito transbordamento de empregos para o restante do país, este setor foi o que mais transbordou em todos os níveis educacionais agregados para o trabalho. Este setor compreende atividades de e gestores de propriedade imobiliária como as de: proprietários de imóveis, agentes e corretores imobiliários que atuam nas atividades de compra, vendam e aluguel de imóveis e outros serviços relacionados como a avaliação de imóveis para qualquer finalidade. Esta seção compreende também as atividades de administração de condomínios, shopping centers e outros imóveis. As atividades 
compreendidas nesta seção podem ser desenvolvidas pelo proprietário do imóvel ou por terceiros sob contrato ou corretagem.

Quando se fala em percentual de participação dos geradores de empregos formais nos setores do estado do Paraná para o ano de 2013 temos que: para o Ensino Fundamental, o setor Produção florestal; pesca e aquicultura (2) apresentou maior participação com 66\%, para o Ensino Médio o setor de maior participação foi o de Outras atividades administrativas e serviços complementares (49) com 67\% e para o Ensino Superior o setor que mais se destacou em participação na geração de empregos foi o de Administração pública, defesa e seguridade social (51) com $62 \%$.

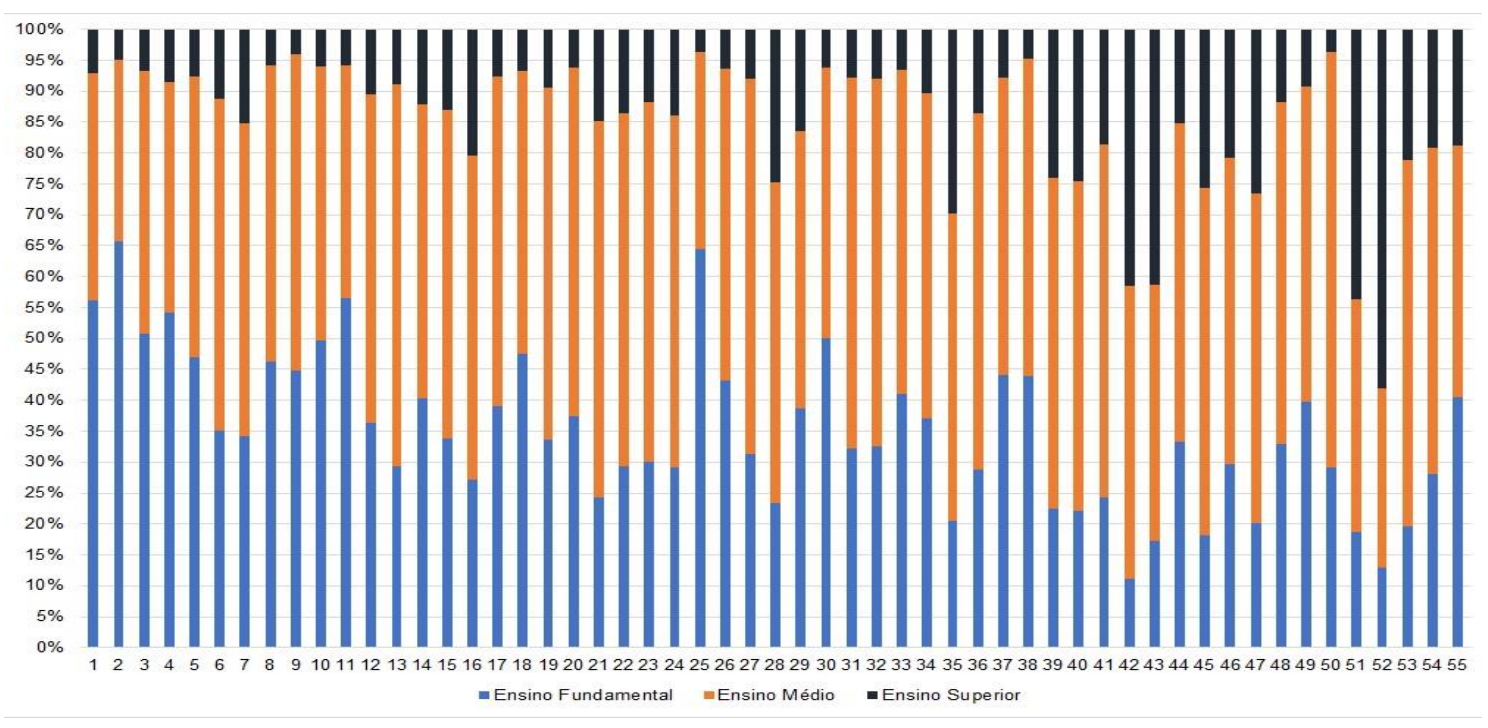

Fonte: o próprio autor

\section{CONSIDERAÇÕES FINAIS}

O presente trabalho propôs inicialmente estimar a geração de emprego por escolaridade no estado do Paraná e Restante do Brasil, buscando classificar quais setores possuem maior capacidade de gerar empregos de acordo com o nível de escolaridade, assim seria possível identificar quais destes setores geram maior transbordamento e maior participação, o resultado mostrará quais setores é a chave para o desenvolvimento econômico e social das regiões.

Para que estes objetivos fossem alcançados o trabalho realizou um levantamento dos aspectos mais importantes referente ao mercado de trabalho e a qualificação dos profissionais, identificando os problemas de baixo investimento em educação que refletem na desigualdade de renda entre as famílias e entendendo que a forma como é distribuída a mão de obra hoje é reflexo do passado. Com isso foi possível traçar a evolução da taxa de desemprego bem como da qualificação dos profissionais e entender os estudos empíricos e seus resultados.

Como metodologia para a pesquisa foi utilizado o sistema insumo-produto para a análise inter-regional, com os resultados nacionais foi possível estimar para cada setor 


\section{DEMANDA SETORIAL DE TRABALHO POR QUALIFICAÇÃO NO PARANÁ}

da economia os multiplicadores e os geradores (total, direto e indireto) a partir dos coeficientes técnicos diretos e da matriz inversa de Leontief inter-regional, no caso específico da matriz estadual destacou-se a importância do efeito transbordamento. A base de dados teve como referência a matriz insumo-produto estimada por Guilhoto e Sesso Filho (2010 e 2005a), com os dados de emprego por qualificação da RAIS (2013), assim a agregação foi feita para 55 setores, ignorando o setor de extração e refino de petróleo por não ter esta atividade no estado do Paraná.

Após realizar a estimação de emprego por escolaridade foi possível afirmar que os setores que mais geraram empregos inter-regionais Paraná-Brasil, para variação de um milhão de reais da demanda final no ano de 2013 com Ensino Fundamental foi Alojamento (37), no Ensino Médio o setor de Atividades de vigilância, segurança e investigação (50) e Ensino Superior o setor Educação Privada (52), estes mesmos setores da análise total são para os geradores de empregos diretos para o Paraná.

Dentre os setores que se destacaram na geração de empregos indiretos do Paraná no ano de 2013, o setor que mais emprega profissionais com Ensino Fundamental é o Fabricação de outros equipamentos de transporte, exceto veículos automotores (25), para Ensino Médio e Ensino Superior o setor que mais emprega é o de Outras atividades profissionais, científicas e técnicas (47). Quando o efeito é induzido pelo gasto de renda das famílias o setor de Atividades imobiliárias (44) é o que mais emprega profissionais com o Ensino Fundamental e o Ensino Médio. Mas para o Ensino Superior o setor destacado é o de Produção florestal; pesca e aquicultura (2).

Para o restante do Brasil quando os efeitos são indiretos o setor que mais emprega mão de obra qualificada com o Ensino Fundamental e o Ensino médio é o de Confecção de artefatos do vestuário e acessórios (9), porém para o Ensino Superior o setor com maior gerador é a Indústria automobilística e peças (24). Também para o restante do Brasil, quando os empregos gerados são induzidos pela renda das famílias o setor Atividades imobiliárias (44) foi o maior gerador de empregos para todos os níveis de educação: Ensino Fundamental, Ensino Médio e Ensino Superior.

Ao analisar qual setor do Estado do Paraná causa o maior transbordamento de empregos para o restante do Brasil, para todos os níveis educacionais ele é o mesmo: Alojamento (44) com 85,9\% para Ensino Fundamental, para o Ensino Médio 87,3\% e para o Ensino Superior $84,4 \%$. Setor este composto por hotéis e similares e outros tipos de alojamentos não especificados, conforme o mencionado o ano em estudo é marcado pelo início do SISU, fato que gerou migrações por todo o país, somente no estado do Paraná chegaram aproximadamente 1.068 estudantes buscando vagas em universidades.

Com isso é possível concluir que: tanto no estado do Paraná quanto no restante do Brasil, quando a mão de obra possui o Ensino Fundamental os setores que mais empregam são os primários como o de extração, produção e fabricação, quanto ao Ensino Médio as atividades são voltadas ao administrativo e fabricação de equipamentos de informática e produtos eletrônicos e quando a qualificação é de Ensino Superior são próximas ao do nível médio, como administração e segurança, envolvidas no setor secundário; foi possível encontrar algumas externalidades, mas no geral é possível analisar os setores econômicos específicos com o grau de qualificação da mão de obra necessários.

Conhecendo os setores que mais geram empregos no Paraná-Brasil, podem ser conduzidas políticas públicas voltadas ao estímulo, com o objetivo de gerar mais emprego com mais produtividade induzindo a um crescimento sustentável, além de incentivar o incremento na qualificação. Este estudo ainda gera preceitos para novas pesquisas voltadas ao impacto da educação na economia, podendo realizar comparações entre as economias estaduais brasileiras baseando na metodologia insumo produto. 


\section{REFERÊNCIAS}

BALASSIANO, Moisés. SEABRA, Alexandre A. LEMOS, Ana H. Escolaridade, Salários e Empregabilidade: Tem Razão a Teoria do Capital Humano? Rio de Janeiro: Rev. RAC, v.9, n.4, 2005.

BARROS, R. P.; CAMARGO, J. M.; MENDONÇA, R. A estrutura do desemprego no Brasil. Rio de Janeiro: IPEA, 1997. (Texto para Discussão, 478).

BRASIL. Decreto-lei $\mathrm{n}^{\mathbf{1}} \mathbf{1 2 . 7 1 1}$ de 29 de agosto de 2012. Disponível em: <http://www.planalto.gov.br/ccivil_03/_Ato2011-2014/2012/Lei/L12711.htm> Acesso em: 13 Junho de 2018.

BRENE, P. R. A.; SESSO FILHO, U. A.; DALLA COSTA. Análise da Viabilidade do Uso de Indicadores Provenientes de Matrizes Insumo-Produto Regionais Estimadas: apresentação e teste da proposta metodológica. Revista Paranaense de Desenvolvimento, v.35, n.127, p.155-180, jul./dez. 2014. Disponível em: http://www.ipardes.pr.gov.br/ojs/index.php/revistaparanaense/article/view/685. Acesso em: 02/02/2018.

CASTRO, Francisco José Gouveia. Crescimento Industrial Paranaense 2011 a 2013. Curitiba: IPARDES, Análise conjuntural, v.37, n.5-6, maio/junho, 2015.

CUNHA, Marina Silva da. Transformações recentes no mercado de trabalho paranaense. Curitiba: Revista Paranaense de Desenvolvimento, n.115, p.79 100, jul/dez $2010 . \quad$ Disponível em: http://www.ipardes.gov.br/ojs/index.php/revistaparanaense/article/view/4/5 Acesso em: 12 Junho 2018.

DEDECCA, Cláudio Salvadori. O desemprego e seu diagnóstico hoje no Brasil. São Paulo: Rev. Economia Política, v.18, n.1, 1998.

DEDECCA, Cláudio Salvadori. Notas sobre a evolução do mercado de trabalho no Brasil. Campinas: Rev. Economia Política, v.25, n.1, 2005.

DEPEN, Departamento Penitenciário. Índices de segurança pública no estado do Paraná, crimes violentos letais e intencionais 2013. Secretaria da Segurança pública. Disponível em: $<$ http://www.depen.pr.gov.br/modules/conteudo/conteudo.php?conteudo=222 $>$ Acesso em: 13 Junho de 2018.

MENDES FILHO, Náecio Aquino Marcos. ALMEIDA, Eduardo Simões. O diferencial de salários formal-informal no Brasil: segmentação ou viés de seleção? Rio de Janeiro: Rev. Brasileira de Economia, v.58, n.2, 2004.

FRIGOTTO, Gaudêncio. CIAVATTA, Maria. Educação básica no Brasil na década de 1990: subordinação ativa e consentida à lógica de mercado. Campinas: Rev. Educação Sociais, v.24, n.82, p.93-130, 2003. 
FERNANDES, Reynaldo. PICCHETTI, Paulo. Uma análise da estrutura do desemprego e da inatividade do Brasil metropolitano. Rio de Janeiro: Rev. Pesquisa Plan. Economia, v.29, n. 1, p.87-112, 1999.

FERREIRA, S. G.; VELOSO, F. A escassez da educação. In: GIAMBIAGI, F; et al. Economia brasileira contemporânea (1945-2004). Rio de Janeiro: Elsevier, 2005.

GUILHOTO, J. J. M. Análise de Insumo-Produto: Teoria e Fundamentos. Unpublished: MPRA_paper_32566, 2011. Disponível em: http://mpra.ub.unimuenchen.de/32566/2/MPRA_paper_32566.pdf. Acesso em: 10 Março 2012.

GUILHOTO, J. J. M.; HEWINGS, G. J. D.; SONIS, M. Productive relations in the Northeast and the rest of Brazil regions in Encontro Nacional de Economia, 1992: decomposition \& synergy in input-output systems. In: 27., 1999, Pará. Anais. Pará: Associação Nacional de Pós-Graduação em Economia, 7 a 10 de dezembro de 1999, p. 1437-1452.

GUILHOTO, J. J. M.; SESSO FILHO, U. A. Análise da estrutura produtiva na Amazônia Brasileira. Amazônia Ciência Desenvolvimento, Belém, v. 1, n. 1, p. 734,2005b. Disponível em <http://www.basa.com.br/bancoamazonia2/revista/007a034.pdf > Acesso em: 12 Março 2010.

GUILHOTO, J.J.M. e SESSO FILHO, U.A. Estimação da Matriz Insumo-Produto Utilizando dados Preliminares das Contas Nacionais: Aplicação e Análise de Indicadores Econômicos para o Brasil em 2005. Economia \& Tecnologia. UFPR/TECPAR. Ano 6, Vol 23, Out. 2010.

GUILHOTO, J.J.M.; SESSO FILHO, U.A. Estimação da Matriz Insumo-Produto a Partir de Dados Preliminares das Contas Nacionais. Economia Aplicada. Vol. 9. N. 2. pp. 277-299. Abril-Junho 2005 a.

IBGE, Senso. Pesquisa Nacional de domicílios. IBGE: 2015.

INEP, Instituto Nacional de Estudos e Pesquisas Educacionais Anísio Teixeira. Microdados do Censo do Ensino Superior 2013. Disponível em: 〈http://portal.inep.gov.br/web/guest/inicio> Acesso em: 13 Junho de 2018.

IPEA, Pnad. Pesquisa Nacional de Amostra de Domicílios. IPEA: 2015.

ISARD, W. Interregional and regional input-output analysis: a model of a spaceeconomy. Review of Economics and Statistics, n.33, p.319-328, 1951.

KON, Anita. Mudanças recentes no perfil da distribuição ocupacional da população brasileira. São Paulo: Revista Brasil, v. 23, p.247-267, 2006.

KURESKI, Rcardo. ROLIM, Cassio. Emprego e Renda no Estado do Paraná por anos de estudo: uma abordagem da matriz insumo-produto. Santa Maria: Rev. De Economia e Desenvolvimento, v.24, n. 2, 2012. 
LEGAT, Angelo Luiz Maurios. Reestruturação produtiva e políticas públicas de emprego e renda no Brasil: o caso do plano estadual de qualificação do Paraná no período de 1996/2000. Florianópolis: UFSC, 2002.

LEONTIEF, W. A economia do insumo-produto. 3. ed. Coleção os Economistas. Nova cultural: São Paulo, 1988.

LETELIER, Maria Eugenia Gálvez. Escolaridade e inserção no mercado de trabalho: um estudo comparativo entre a Grande São Paulo (Brasil) e a Grande Santiago (Chile). São Paulo, Pontifícia Universidade Católica de São Paulo, 1999 (Tese de Doutoramento).

MANFREDI, Silvia Maria. Trabalho, qualificação e competência profissional - das dimensões conceituais e políticas. Campinas: Revista Educação e Sociedade, v.19, n.64, 1998.

MEC, Ministério da Educação. Programas e Ações. MEC, 2013.

MILLER, R.E. e BLAIR, P.D. Input-output analysis: foundations and extensions. Englewood Cliffs: Prentice-Hall, 2009.

MOTA, Maria K. BARBOSA, Renato S. FILGUEIRA, João M. Desenvolvimento regional baseado na educação: uma análise insumo-produto no estado do Rio Grande do Norte - Brasil. Rio Grande do Norte: Rev. Brasileira de Gestão e Desenvolvimento Regional, v.11, n. 1, 2015.

NEREUS - Núcleo de Economia Regional e Urbana da USP. Sistema de Matrizes de Insumo-Produto, Brasil (56 setores). Disponível em: http://www.usp.br/nereus/?fontes=dados-matrizes. Acesso: 07 Fevereiro 2014.

PEROBELli, Fernando S. BASTOS, Suzana Q. A. PEREIRA, Marcilio Z. Decomposição estrutural por grau de instrução: uma análise de insumo-produto para o período pós-abertura (1990 a 2005). Belo Horizonte: Rev. Nova Economia, v.26, n.3, p. 909-942, 2016.

RAIS - Relação Anual de Informações Sociais/MTE. Disponível em: http://bi.mte.gov.br/bgcaged/login.php. Acesso: 07 Fevereiro 2014.

RAIS / CAGED. Bases Estatísticas para os anos de 2009 e 2014. Disponível em: http://sgt.caged.gov.br/index.asp. Acesso: 07 Fevereiro 2014.

RAMOS, L.; MENDONÇA, R. Pobreza e desigualdade de renda no Brasil. In: GIAMBIAGI, F. et al. Economia brasileira contemporânea (1945-2004). Rio de Janeiro: Elsevier, 2005.

RAMOS, L. BRITTO, M. O funcionamento do mercado de trabalho metropolitano brasileiro no período de 1991-2002: tendências, fatos estilizados e mudanças estruturais. Rio de Janeiro: IPEA, 2004.

RICHARDSON, H. W. Insumo-Produto e Economia Regional. Rio de Janeiro: Zahar Editores, 1978. 
SACHSIDA, Adolfo. LOUREIRO, Paulo Roberto A. MENDONÇA, Mário Jorge C. Um estudo sobre retorno em escolaridade no Brasil. Rio de Janeiro: Rev. RBE, v.2, n.58, p. 249-265, 2004.

SESSO FILHO, U. A.; KURESKI, R.; MORETTO, A. C.; RODRIGUES, R. L.; BALDUCCI, F. L. P. Indústria automobilística no Paraná: impactos na produção local e no restante do Brasil. Revista paranaense de desenvolvimento, Curitiba, n.106, p.89-112, jan./jun. 2004. Disponível em: http://www.uel.br/pos/economia/material/2\%20ECO\%20113/umberto.pdf. Acesso em: 20 Abril 2010.

SESSO FILHO, U. A.; MORETTO, A. C.; RODRIGUES, R. L. e GUILHOTO, J.J.M. Interações Sinérgicas e transbordamento do efeito multiplicador de produção das grandes regiões do Brasil. Economia Aplicada vol.10 no.2 Ribeirão Preto Apr./June 2006. Disponível em: http://www.scielo.br/pdf/ecoa/v10n2/a05v10n2.pdf. Acesso em: 20 Abril 2010. 